\title{
Reflective Practice: A Gateway to Professional Development
}

Shiva Ram Pandey

\begin{abstract}
The main purpose of this research paper is to explore the power of reflection in the teaching and learning process. The prime research question is how do English language teachers reflect their opinion and experience in reflective practice? This research is a qualitative study of English teachers from the Kathmandu district higher secondary schools. The results of this study show that reflective practice enhances teaching skills and brings changes in instructional practices. Teachers have to think, act and reflect tenaciously. As a result, the instructional process is activated and improved. It further presents that every incident has enormous insights to learn through this practice. Reflective practice enhances the professional development of English language teachers.
\end{abstract}

Key words: Pondering, Planning, Reflection, Perfection, Professionalism

While pondering on reflective teaching, I would like to remember the philosophical idea of Dewey (1933) who called for teachers to take reflective action that entails "active, persistent, and careful consideration of any belief or supposed form of knowledge in light of the grounds that support it and the further consequences to which it leads" (p. 9).

Furthermore, he identified three attributes of reflective individuals, which are still important for teachers today: open-mindedness, responsibility, and wholeheartedness. Open-mindedness is a desire to listen to more than one side of an issue and to give attention to alternative views. Responsibility involves careful consideration of the consequences to which an action leads. Wholeheartedness implies that teachers can overcome fears and uncertainties to critically evaluate their practice in order to make a meaningful change. He considered it to be a special form of problem solving, thinking to resolve an issue which involved active chaining, and a careful ordering of ideas linking each with its predecessors.

Chaudhary (2008) in his article "reflection as a key concept for teacher development" concludes that reflection is a means through which teacher development takes place. It is a very useful tool for meditation. It can also be called the flash back method. Reflection in teacher development can be the best way to explore teachers' hidden identity. It is helpful to discover our own unconscious and unexplored potential. It helps us to modify our ritual knowledge. It involves a major shift in emphasis on our thinking and acting. The relationship between teacher 
development and reflection is important.

Reflective practice is a meditative process of learning the language. It provides the response to an event. Generally when we start thinking, it gives birth to creativity. It enables teachers to assert their professional identity as change agents with moral purposes and it is essential to self-knowledge. It is a problem solving activity. It involves a critique of practice; the values that are implicit in that practice; the personal, social, institutional and broad policy contexts in which practice takes place; and the implications of these for improvement of that practice. It is an essential means of reexamination and renewal of passion by those who care about their work, who are captivated by their pupils' potential for learning.

Reflective practice seeks to offer a dynamic, reliable, and viable means by which the teacher can develop his or her professionalism, because it is teacherinitiated and teacher-directed: it involves teachers observing themselves, collecting data about their own classrooms and their roles within them, and using the data as a basis for self-evaluation and change and their professional growth (Richards and Lockhart, 1994).

Schon (1978) introduced the concept of Reflection-in-action and Reflectionon-action. Reflection-in-action can be described as the ability of a practitioner to 'think on their feet', otherwise known as 'felt-knowing. It revolves around the idea that within any given moment, when faced with a professional issue, a practitioner usually connects with their feelings, emotions and prior experiences to attend to the situation directly. Reflection-onaction is the idea that after the experience a practitioner analyses his or her reaction to the situation and explores the reasons around, and the consequences of his or her actions. This is usually conducted through a documented reflection of the situation. In this connection, Brookfield (1995) contended:

Through reflection, a teacher becomes better able to justify and explain educational actions to self and others. Reflection aids educators in speaking about their practice in a confident and informed manner. I used to think I'd be a great reflective teacher. I had visions of spending time at the end of each day replaying my classes to see what worked and what didn't, etc., but quite honestly, by the end of the day. I am so frazzled from just trying to keep up. I can hardly even remember what took place only hours ago. And most of the time, I am so worried about tomorrow. I don't even want to think about yesterday or today. I've taken to doing things for myself in the evenings now in order to get my mind off (as cited in Cole, 1997, p.9).

The ways of developing reflection are daily journal or teacher's diary, cross disciplinary sharing, observation, recording lesson and student feedback. Reading the reflections of others aid in self-realization. By reading the reflections of others, it always helps me in self-improvement. It also prevents repetition of the same mistake.

\section{Method of the study}

My ontology in this study is that there are multiple realities pertaining to reflective practice from the perspective of teachers. The epistemology of this study is that 
knowledge regarding reflective practice is subjective. The research methodology of this study is qualitative. The site and sample are higher secondary English teachers from the Kathmandu district. During the study, the participants' real names have not been disclosed in accordance with research ethics. The data is interview-based. Openended questions were used to explore the subject of reflective practice, what it does and how it contributes to the professional development of teachers. Analysis of the data was conducted inductively.

\section{Reflections on reflection}

Pandey (2007) has conducted a research on, "a study on the reflective practice of secondary level English teachers" and found that language teachers have positive attitudes towards reflective practices though they are not trained in reflective practice formally. Similarly, he found that many language teachers do not record their best way of teaching. He has also recommended some ideas from the findings of the research. $\mathrm{He}$ recommended that all the in-service teachers should be provided training in reflective practice and the teacher's training courses should include reflective model to some extent. He has also recommended that teacher support group should be managed within a school and among schools to share their opinions about their own strengths and weaknesses between colleagues and to attend in reflective conversation.

It is through audio-visual aids that language teachers can better present language materials. However, it is truly difficult to manage such information to make the instructional process really instrumental.

Similarly, Phuyal (2008) has carried out his research on, "a study on teacher development through reflective teaching: perceptions and practices of English language teachers" and found a very deplorable condition of the use of reflective practice in English language teachers' situation. He found them not practicing the tool of reflective teaching as a means of their professional development. They were found having various constraints to implement the tools of reflection in English classrooms as a way to their professional development.

However, teachers had shown positive attitudes towards its use in the classroom. Moreover, they tend to blame others for their inability to implement reflective practice in the classroom. They are not so cooperative and supportive to their colleagues to enhance reflective practices in their classrooms. They do not seem to make use of their learners' constructive feedback in their professional development.

Reflective practice appears as a solution to a problem. It helps language teachers to solve problems.

Pertaining to what reflection is, Teacher B says:

Reflection is essential in language teaching. Even after finishing the class, one should go back to the class and ask questions to oneself. For instance whether students understood my class or not, whether the methods went well or not, whether the materials are abundant or not, and whether the objectives are successfully achieved or not. In my case, when I am not satisfied with my teaching, I change methods, use materials. As a language teacher I have experienced failure many times. Reflective teaching gives me an 
opportunity to improve my weaknesses to become a reflective and professional teacher.

Both teacher $\mathrm{A}$ and $\mathrm{C}$ agree with what teacher B said in matter of what reflective practice is. Through recalling and self- assessment, teachers can develop professionalism. The language teacher has to ask questions to herself or himself. With this technique, language instructors can assess their weaknesses and strengths.

Each moment is momentous in the teaching and learning process. Being a language teacher requires remembering important moments as good source of learning to further the horizon of knowledge. Therefore, the language teacher has to create such situation in the classroom at the time of teaching.

In this connection teacher A who is an M.Ed in English, and an experienced teacher, has been teaching English for ten years, makes the following statement:

Teachers must evaluate their performed work, analyze the situation they have lived through; explore the understandings they have brought through their work to prepare themselves for their future action into the classroom. Reflective practices help professional teachers to correct their ill practice.

The reflective theory supports planning, action and reflection. Research on effective teaching over the past two decades has shown that reflective practice is linked to inquiry, reflection, and continuous professional growth. Reflective practice can be a beneficial form of professional development at both the pre-service and inservice levels of teaching. By gaining a better understanding of their own individual teaching styles through reflective practice, teachers can improve their effectiveness in the classroom.

Teaching is a reflective process (Underhill, 1991). Teachers need to be continuously reflecting on and developing their work, not only because change keeps coming from outside, but because knowledge is continuously changing and developing and no schools or teachers can afford to erode skills and knowledge they have learnt formally or informally is reflected in action into the classroom. Reflective practices help professional teachers to correct their ill practice.

Teacher development is the process of becoming the best teacher as far as possible. To equip teachers with the knowledge, attitudes, behaviors and skills, they require performing their tasks effectively in the school and classroom. Teachers want the best for their students. Teacher development involves personal, professional and social development.

In this fast changing global scenario, no other processes except for reflective practice, could serve the ever growing needs of the English language learners and teachers by integrating both theory and practice (Bartlett, 1990).

Current teacher education needs innovative changes. Reflectivepracticeinacollaborative culture helps teachers grow in their job. Teachers can develop professionally and personally if they understand themselves and their own actions. They need to look into their beliefs, values and attitudes and how they affect their classroom practices in which reflective practice is the main 
principle. Investigation is easier and more productive if it is done collaboratively.

There is hardly any bigger joy than the joy of reflectivity. The job of teaching is the collection of experiences. Experience is the best reflective teacher. Reflection is the motivating gateway and headway to professional development of teachers, no matter how well they teach; there is always room for improvement. The reflective habit helps teachers to reveal the reality of the teaching and learning process.

\section{Significance of reflective practice}

Here I would like to acknowledge my colleague for his invaluable insights regarding the significance of reflective practice. He has done his M.Ed. in English. He has got five years of teaching experiences and profoundly produces the following remarks:

All teachers have struggled from time to time with their job as they want to improve the teaching learning process. They spend time, money and effort by attending varieties of training. They receive feedback from others then improve a little bit. But, after sometime, there is no one to help them continuously. It is only them who can decide whether to improve continuously or not. And the solution is becoming a reflective teacher. Teachers who examine their own teaching through reflection develop positive attitudes and awareness which can benefit their professional growth as teachers, as well as improve their support for students' learning.

Reflective teaching is extremely valuable as a stance, state of mind, and a healthy, questioning attitude towards the practice of teaching profession. It is worth doing because it creates a context which promotes professional development. The reflective approach promises to address this need. It is an 'insider' approach or 'self-directed' approach (Richards and Farrell, 2005).

In other words, in the reflective approach, the teacher experiences knowledge: he or she constructs his or her own theories of teaching, drawing on his knowledge, skills, training, and his own experience of teaching. His or her professional growth takes place through the process of critical reflection that this involves. This is in marked contrast to the widely prevalent applied science model in which the teacher merely receives knowledge and applies it.

At this juncture, Brubacher and his colleagues, in answer to the question why does a teacher devote time and energy to becoming a reflective practitioner? And suggest three principal benefits: reflective practice helps to free teachers from impulsive, routine behaviour; it allows teachers to act in a deliberate, intentional manner; and it distinguishes teachers as educated human beings since it is one of the hallmarks of intelligent action (Brubacher et al., 1994, p.25).

\section{Obstacles and opportunities}

Motivation is a gateway to enter into the ocean of knowledge. It is a driving force to further and develop knowledge. Another big challenge before educators is that it is very difficult to reflect and motivate in a large number of audiences. Teacher B says that he is not able to manage time for reflection. To further illustrate this, he says:

I have problems with teaching strategies. I am not successfully able to motivate the 
students. In the case of me I have problem with time. I feel afraid of reflecting before the seniors.

Some educators feel they are not truly studious enough to tackle the situation. A sense of responsibility is lacking. The ground of thinking can be low and slow. Many think very much one- sided. Teacher C who is an M.Ed. in English, is an experienced teacher. He, in this connection is compounded by many problems which he presents in the following ways:

Time consumption thought, motivation factor, lack of analytical type of thinking, less study habit, hesitation, lack of social responsibility, lack of subject matter etcetera are some of the problems we are facing in general.

He seems to be worried about time. Teachers, who have to teach in different colleges, make a hurried trip in the process of teaching and learning. The problem among us is that we always blame other people but we do not blame to ourselves. It means we put a question mark in others' activities but we do not raise the voice of our shortcomings. Until and unless this culture rules the language teachers, they cannot better reflect in the language. Teacher $\mathrm{B}$ says that busy teachers can't reflect well. To illustrate it further, he says:

One can't teach in hustle and bustle. What I feel is busy teacher doesn't have time to think. She or he thinks of her or his motorcycle to go to another college after she or he finishes the class in one college. In my case, I am not motivated because there is scarcity of materials, resources and remuneration. However, it is a great matter of opportunity to reflect my inner tenacity.
It is very interesting to know that teachers who have busy schedule can't be a professional teacher. Determination towards the profession is really important to become a professional person rather than simply becoming an easy teacher. However, one shouldn't be disappointed with this problem. One should understand that problem also contains progress. It is important to note that reflective practice helps to identify the individual talent, who we are, what we do and how we do the activities. It brings the abstract into the practical. This is the beauty of reflective practice.

There aren't any places without problems. Again, it can be said that where there is a problem there is a solution. We shouldn't forget the fact that today's problems come from yesterday's solutions. In this case, we should solve the problems very wisely and carefully. As language teachers, we should identify the problem on time and solve it very tactfully. In this connection, Teacher A says:

Lack of English environment, time management, motivation, superiority complex, political invasion, feeling shame to express in English etc are some of the forces that deter from doing the reflective practice. When these problems are solved, there will be the improvement in the reflective practice of English teachers. Still, it helps to solve the problem.

It is very difficult to reflect in a large number of students. Some students are very shy. They don't like to interact. Sometimes educators feel shy to reflect before senior colleagues. A lack of experience matters a lot. Managing time with friends is also a 
problem which affects language teachers from being reflective practitioners. A lack of motivation affects language teaching.

In spite of all these difficulties, it helps the language teacher to reveal the reality, participate in problem solving activities and enhance the level of sharing among friends, colleagues and teachers. Therefore, teachers should be motivated to reflect more in the teaching and learning process to develop professionally.

Teaching is clearly understood as an activity that is situated in a particular time and place (Freeman, 1996). Because teaching is a situated activity, it requires teachers to figure out how to teach a particular topic, with a particular group of students, at a particular time, in a particular classroom, within a particular school (Johnson, 1999).

Therefore, we need to activate our hearts, heads and hands to take part in the exercise of doing the reflective practices. The moment we share our success story to others, they will benefit from it. Presentation skills develop engagement in reflective activities. Each incident involves insights to energize and enlighten the perspectives of knowledge.

\section{Epilogue}

The language teacher has to think, plan, meditate, act, assess and evaluate himself or herself. A reflective teacher becomes critical and creative too. Questioning skills develop and they do not take things as for granted. Therefore, being reflective means having all these qualities. The significance of this study is to learn how to be a reflective teacher. Some teachers do not have the habit of reflecting language materials before others and even at the time of meeting. English language teachers do not dare to share and reflect feelings at the time of meetings. However, it requires involvement in the activities of reflective practice. The demand of time is that educators have to make it a habit to achieve success in the academic and teaching life of a teacher.

Teachers of English, do not reflect much regarding their strengths and weaknesses. In this research study, it has been discovered that reflective teaching is a new concept. Later, in professional life, the reflective habit brings a significant change in the level of thinking and in the horizon of knowledge. It helps educators to reflect in the language while interacting with friends and colleagues. It is truly a great matter of joy to reflect one's own opinions and experiences. This is possible through reflective practice. For the language teacher, it is an indispensable vehicle to create successful and meaningful teaching.

Reflective process is one in which every aspect of the English teacher education experience becomes open to critical examination and reconsideration. When teachers question their own assumptions about themselves, teaching, learners and learning, they begin to recognize the consequences of their beliefs, knowledge and experiences on their own teaching.

The duty of the teacher of English is not just to teach English texts, but also to help students with other skills like communicative, analytical, and logical skills. To be able to deal with the growing demands on the English teacher, timely orientation towards professionalism is of dire importance. It has been found that 
methodology, training and concept alone will not make a teacher competent enough to train students at college level to meet their requirements. In this fast changing global scenario, no other processes, except for reflective practice, could serve the ever growing needs of the English language learner and teacher by integrating both theory and practice. However, the need of reflective practice is to assess and evaluate our weakness and strength in teaching.

Therefore, through reading the reflections of others, it helps us to improve ourselves and learn from mistakes. The reading of reflections spurs to improve because it gives ideas of what is expected by others in teaching and learning process. By reading other people's weaknesses and strengths indirectly helped teachers in choosing which method to use, what kinds of mistakes need to be avoided and also how to bring in front of older audience.

The main purpose of teaching is to reflect the reality. In the case of a language teacher, it is a must. As it is commonly said that to die is better than to lie, in that case if a teacher speaks lies he or she is producing the liars. Reflective practice helps teachers to become truthful.

In that sense, educators do not have to be afraid of revealing the weaknesses since they contain strength. The importance of reflection is to reveal such hidden weaknesses before others. This is the reason that the joy that comes from reflectivity is crucial in teaching and learning activity.

As a language teacher, the duty and responsibility is to prepare students to become honest and truthful. This is possible through reflective practice.
English language teachers have been living in suffocation. They hide their problems. They do not release them. As a result, they suffer a lot. If they really reveal their pain, they can certainly gain a lot of information. A teacher has to be crystal clear in the matter of expressing the mountains of materials. Thus, professional development of teachers is possible through reflective practice. Revealing the reality is the essence of reflective practice. However, it is not the only panacea. There are other factors that also affect professional development of teachers. Reflection, therefore, is the ability to convert the abstract into the practical and the idea into action. Thinking back and moving ahead with action is reflection. It leads to invention. It is a mulling process. It generates new ideas to learn better. It is also a heutagogical practice of directing one's learning and practice.

\section{About the author}

Shiv Ram Pandey, a life member of NELTA is a lecturer of English Education at Gramin Adarsha Multiple Campus, Kathmandu, Nepal. He has received PhD in Education from Kathmandu University, Dhulikhel, Nepal. He has published articles in the academic journals. He is a researcher, trainer and educator as well. He has taught from nursery to tertiary level students. He has been researching for seven years in diverse disciplines. He considers teaching as passion, patience and perseverance.

\section{References}

Bartlett, L. (1990). Teacher development through reflective teaching. Cambridge University Press.

Brookfield, S. D. (1995). Becoming a critically reflective teacher. San Francisco:Jossey-Bass.

Brubacher, J. W., Case, C. W., and Reagan, T. G. (1994). Becoming a reflective educator: How to build a culture of inquiry in the schools. California: Corwin Press.

Chaudhary, D. R. (2008). Reflection as a key concept for teacher development, vol.13.No.1-2. Journal of NELTA. Kathmandu. 
Dewey, J. (1933). How we think. Madison: University of Wisconsin Press. Elias, J. Merriam, S. (2005). Philosophical foundations of adult education Malabar, F Krieger.

Freeman, D. (1996). Redefining the relationship between research and what teachers know. In K. M. Bailey \& D. Nunan (eds). Voices from the language classroom (pp.88-115). NewYork: Cambridge University Press.

Johnson, K.E. (1999). Understanding language teaching: Reasoning in action. Boston:Heinle \& Heinle.

Pandey,H.L.(2007). A study on the reflective practices of secondary level English language teachers. An unpublished M.Ed. thesis. Tribhubhan University. Kathmandu, Nepal.
Phuyal, G.P. (2008). A study on teacher development through reflective teaching: Perceptions and practices of English language teaching. An unpublished M.Ed. thesis. Kathmandu Universiy. Nepal

Richards, J. C., \& Farrell, T. S. C. (2005). Professional development for language teachers. New York: Cambridge University Press.

Richards, J. C., \& Lockhard, C. (1994 ). Reflective teaching. New York: Cambridge University Press.

Scon, D. (1978). Educating the reflective practitioner. San Francisco: Jossey-Bass.

Underhill, A. (1991). Best of British ELT. Plenary talk on Teacher Development 


\section{Appendix}

1. How do you ponder on reflection?

2. How do you perceive on reflective practice?

3. How does reflective practice contribute for the professional development of English language teachers?

4. Why is reflective practice important for the professional development of English language teachers?

5. What obstacles have you faced in reflective practice?

6. What opportunities have you seen in reflective practice?

7. What will be the future of English language teachers in reflective practice? 